\title{
ANALISIS PROFITABILITAS DAN EFISIENSI BIAYA USAHA MIKRO KECIL MENENGAH PENGOLAHAN SALAK "WEDI" DI DESA WEDI KECAMATAN KAPAS KABUPATEN BOJONEGORO
}

\author{
PROFITABILITY AND COST EFFICIENCY ANALYSIS OF SMALL MEDIUM MICRO \\ BUSINESS PROCESSING "WEDI" SNAKEFRUIT IN WEDI VILLAGE KAPAS \\ DISTRICT BOJONEGORO REGENCY
}

\author{
LUKMAN*, NURIAH YULIATI, EKO PRIYANTO \\ Fakultas Pertanian, Universitas Pembangunan Nasional "Veteran" Jawa Timur \\ *E-mail : lukmanmia411@gmail.com
}

\begin{abstract}
ABSTRAK
Desa Wedi merupakan desa sentra produksi salak di Kecamatan Kapas Kabupaten Bojonegoro. Salak "Wedi" yang berkualitas rendah atau memiliki rasa asam dan sepet diolah menjadi kurma salak dengan tujuan untuk meningkatkan nilai jual melalui UMKM. Peran UMKM pengolahan kurma salak "Wedi" sangat penting, selain memberikan nilai tambah juga berperan mensejahterakan masyarakat, membuka lapangan kerja, wahana pemerataan ekonomi masyarakat, dan peningkatan pendapatan nasional. UMKM pengolahan kurma salak "Wedi" harus menjaga efisiensi dan profitabilitas agar dapat mempertahankan keberlangsungan usaha. Tujuan penelitian ini adalah untuk menganalisis profitabilitas dan efisiensi UMKM pengolahan kurma salak "Wedi". Metode yang digunakan untuk menganalisis profitabilitas dan efisiensi biaya adalah analisis kuantitatif. Analisis efisiensi biaya menggunakan metode Data Envelopment Analysis. Data primer dikumpulkan melalui kuesioner dan wawancara. Sampel berjumlah 3 UMKM pengolahan kurma salak "Wedi" yang ditentukan melalui teknik sampling jenuh. Hasil penelitian menunjukkan bahwa besar profitabilitas masing-masing UMKM Pengolahan kurma salak "Wedi" yaitu UMKM Bunda Arum sebesar 28,38\%, UMKM Shanum sebesar 40,33\%, dan UMKM Barokah sebesar 59,19\%. Perhitungan efisiensi biaya pada semua UMKM pengolahan kurma salak "Wedi"menggunakan metode Data Envelopement Analysis diperoleh skor $100 \%$. sehingga semua UMKM pengolahan kurma salak "Wedi" di Desa Wedi yang masih bertahan telah efisien. UMKM Pengolahan kurma salak "Wedi" harus mempertahankan dan meningkatkan profitabilitas dan efisiensi biaya untuk mempertahankan keberlangsungan usaha.
\end{abstract}

Kata Kunci: Profitabilitas, Efisiensi, UMKM, Salak "Wedi"

\begin{abstract}
Wedi Village is a snakefruit production center village in Kapas District, Bojonegoro Regency. "Wedi" snackfruit which is of low quality or has a sour and bitter taste is processed into snakefruit dates with the aim of increasing the selling value through MSMEs. The role of UMKM in processing "Wedi" snakefruit dates is very important, in addition to providing added value, it also plays a role in the welfare of the community, opening up employment opportunities, as a vehicle for equitable distribution of the community's economy, and increasing national income. SMEs processing snakefruit dates "Wedi" must maintain efficiency and profitability in order to maintain business continuity. The purpose of this study was to analyze the profitability and efficiency of SMEs processing snakefruit dates "Wedi". The method used to analyze profitability and cost efficiency is quantitative analysis. Cost efficiency analysis using Data Envelopment Analysis method. Primary data were collected through questionnaires and interviews. The sample amounted to 3 SMEs processing snakefruit dates "Wedi" which was determined through saturated sampling technique. The results showed that the profitability of each MSME in the processing of snakefruit dates "Wedi" namely MSME Bunda Arum was 28.38\%, MSME Shanum was 40.33\%, and MSME Barokah was 59.19\%. Calculation of cost efficiency in all SMEs processing snakefruit dates "Wedi" using the Data Envelopement Analysis method obtained a score of 100\%. so that all MSMEs processing "Wedi" salak dates in Wedi Village
\end{abstract}


that still survive are efficient. SMEs Processing salak dates "Wedi" must maintain and increase profitability and cost efficiency to maintain business continuity.

Kewords: Profitability, Efficiency, MSMEs, "Wedi" snakefruit

\section{PENDAHULUAN}

Desa Wedi merupakan salah satu desa di Bojonegoro yang menjadi sentra produksi salak. Salak yang di produksi di Desa Wedi memiliki nama salak "Wedi". Salak "Wedi" yang mempunyai rasa asam dan kecut tidak mampu bersaing dan jika dijual harganya sangat rendah. Oleh karena itu perlu dilakukan pengolahan melalui UMKM untuk meningkatkan nilai tambah dan memberikan nilai jual dari buah salak "Wedi".

UMKM adalah usaha produktif yang berdiri sendiri yang dilakukan oleh perorangan atau kelompok atau badan usaha disemua sektor ekonomi. UMKM memiliki peran penting antara lain mensejahterakan masyarakat, membuka lapangan kerja, wahana pemerataan ekonomi masyarakat, dan peningkatan pendapatan nasional (Renstra Kemenkop RI. 2012). Sayangnya, peran UMKM pengolahan salak "Wedi" dalam mengurangi tingkat pengangguran di Indonesia tidak berlangsung lama di Desa Wedi. Seiring bertambahnya tahun, satu persatu UMKM pengolahan salak "Wedi" meninggalkan produksi. Berdasarkan hasil wawancara dengan perangkat Desa Wedi mengatakan pada tahun 2017 terdapat 21 UMKM pengolahan salak "Wedi". Hingga pada tahun 2020 tersisa 3 UMKM pengolahan salak "Wedi" yang masih produksi. Sedangkan 18 UMKM pengolahan salak "Wedi" tidak melakukan produksi.

Permasalahan tersebut kemudian mendorong pelaku usaha pengolahan kurma salak "Wedi" yang masih bertahan untuk mempertahankan keberlangsungan usaha dengan cara memperhatikan efisiensi dan profitabilitas produksi. Perusahaan dengan rasio profitabilitas yang tinggi mengindikasikan bahwa perusahaan tersebut berjalan dengan baik sehingga dapat mempertahankan kelangsungan hidupnya. Pearce dan Robinson (2008) mengatakan pertumbuhan suatu perusahaan sangat terkait dengan kelangsungan bisnis serta profitabilitasnya. Selain itu Darsono dan Ashari (2005) menyebutkan salah satu faktor yang menyebabkan kebangkrutan pada perusahaan adalah manajemen yang tidak efisien. Tujuan penelitian ini adalah untuk menganalisis profitabilitas dan efisiensi biaya produksi kurma salak "Wedi" di 
UMKM pengolahan salak "Wedi" yang masih bertahan dan melakukan produksi.

\section{TINJAUAN PUSTAKA}

\section{Biaya Produksi}

Biaya produksi merupakan biaya yang dikeluarkan dalam proses produksi sampai menjadi output. Menurut Fahmi (2014) mengatakan biaya dalam hubungannya dengan volume produksi yaitu :

1. Biaya tetap (Fixed Cost) adalah biaya yang nilainya tidak akan berubah dari satu proses produksi ke proses produksi berikutnya walaupun volume produksi yang dihasilkan berubahubah.

2. Biaya Variabel (Variabel Cost) artinya biaya yang jumlah, nilai dan komposisi biaya variabel ini dapat diubah apabila volume atau komposisi barang yang akan dihasilkan dalam satu proses produksi akan berubah

Menurut Firdaus (2008) Biaya total yaitu keseluruhan jumlah biaya produksi yang dikeluarkan. Secara matematis biaya total dapat dirumuskan sebagai berikut:

$$
\mathbf{T C}=\mathbf{T F C}+\mathbf{T V C}
$$

Keterangan:

TC = Biaya total

TFC = Total biaya tetap

$\mathrm{TVC}=$ Total biaya variabel

2. Penerimaan
Menurut Yogi (2006) Penerimaan total secara langsung ditentukan oleh jumlah produk yang terjual dan yang diterima. Secara matematis dirumuskan sebagai berikut :

$$
\mathbf{T R}=\mathbf{P} \times \mathbf{Q}
$$

Dimana :

TR $($ Total Revenue $)=$ Penerimaan total

$\mathrm{P}$ (Pricie) = Harga produk

$\mathrm{Q}$ (Quantity) = Jumlah output

\section{Keuntungan}

Menurut Reeve, et al, yang dialih bahasakan oleh Dian (2011:3) keuntungan atau laba (Profit) adalah selisih antara uang yang diterima dari pelanggan atas barang dan jasa yang dihasilkan dengan biaya yang dikeluarkan untuk input yang digunakan guna menghasilkan barang atau jasa. Secara matematis dapat ditulis sebagai berikut (Rahim dan Hastuti. 2007)

$$
\boldsymbol{\pi}=\mathbf{T R}-\mathbf{T C}
$$

Keterangan:

$\pi$ (Profit) = Keuntungan

TR $($ Total Revenue $)=$ Penerimaan total $\mathrm{TC}($ Total Cost $) \quad=$ Biaya total industri

4. Profitabilitas

$\begin{array}{ccr}\text { Menurut } & \text { Sutrisno } & (2009: 16) \\ \text { Profitabilitas } & \text { adalah } & \text { kemampuan } \\ \text { perusahaan } & \text { dalam } & \text { menghasilkan } \\ \text { keuntungan } & \text { dengan semua } & \text { modal yang }\end{array}$


bekerja di dalamnya. Menurut Ibrahim (2003), profitabilitas usaha secara matematis dapat dirumuskan sebagai berikut :

$$
\text { Profitabilitas }=\frac{\pi}{T C} \times 100 \%
$$

Keterangan :

$\Pi($ Profit $) \quad=$ Keuntungan $(\mathrm{Rp})$

TC $($ Total Cost $)=$ Biaya Total $(\mathrm{Rp})$

\section{Efisiensi}

Efisiensi dapat diukur melalui menggunakan teknik perhitungan seperti Data Envelopment Analysis (DEA). DEA berfungsi untuk mengukur efesiensi suatu organisasi yang melibatkan banyak input dan banyak output(multi input multi output) (Indah Susilowati, et.al, 2004). Menurut Anggraita (2012), metode Data Envelopment Analysis (DEA) merupakan suatu metode analisis non parametrik yang khusus digunakan untuk mengukur efisiensi unit kegiatan ekonomi yang dinamakan Decision Making Unit (DMU). Metode DEA mampu menganalisis banyak input dan banyak output (multi input-multi output) dengan menggunakan program linier guna menghasilkan nilai efisiensi tunggal untuk setiap DMU.

\section{METODE PENELITIAN}

Penelitian ini dilakukan di Desa Wedi Kecamatan Kapas Kabupaten Bojonegoro. Dengan objek penelitian adalah UMKM
Pengolahan Kurma salak "Wedi" yang masih bertahan. Penelitian dilakukan pada bulan Mei 2021.

Sampel ditentukan dengan teknik sensus. Sugiyono (2018) mengemukakan bahwa teknik sensus adalah teknik penentuan sampel bila semua anggota populasi digunakan sebagai sampel. Hal ini sering dilakukan apabila populasi kecil, kurang dari 30 orang (Supriyanto dan Machfudz. 2010). Sehingga sampel yang digunakan dalam penelitian ini adalah seluruh populasi UMKM pengolahan salak "Wedi" yang masih bertahan dan melakukan produksi yaitu sebanyak 3 UMKM pengolahan salak "Wedi".

Data yang dikumpulkan berupa data primer yang berasal dari kuesioner, wawancara dan observasi terhadap UMKM Pengolahan kurma salak "Wedi" yang masih bertahan. Metode analisis data yang digunakan adalah analisis kualitatifkuantitatif yang bersifat deskriptif, yaitu penelitian yang berusaha mendeskripsikan suatu gejala, peristiwa, dan kejadian yang terjadi saat ini. Analisis kuantitatif mencakup analisis profitabilitas dan analisis Efisiensi Biaya UMKM Pengolahan kurma salak "Wedi".

Cara mengukur profitabilitas dengan menggunakan persamaan sebagai berikut:

$$
\text { Profitabilitas }=\frac{\pi}{T C} \times 100 \%
$$


Keterangan :

$\Pi=$ Keuntungan $(\mathrm{Rp})$

$\mathrm{TC}=$ Biaya Total $(\mathrm{Rp})$

Menurut Ibrahim (2003) kriteria yang digunakan dalam perhitungan profitabilitas adalah :

Profitabilitas $>1$ berarti menguntungkan

Profitabilitas $=1$ berarti BEP (impas)

Profitabilitas < 1 berarti tidak menguntungkan

Cara mengukur efisiensi UMKM pengolahan salak "Wedi" menggunakan model Data Envelopment Analysis (DEA) dengan bantuan Software Frontier Analysis dengan kriteria pengukuran menurut Santoso (2010) :

1) $0-89,9 \%$, Red $\rightarrow$ Tidak Efisien

Keterangan :

Kondisi proyek beresiko karena jauh dari skor yang ingin dicapai sehingga perlu adanya tindakan manajemen

2) $90-99,99 \%$, Amber $\rightarrow$ Tidak Efisien

Keterangan :

Kondisi proyek mungkin beresiko jika permasalahan yang ada tidak segera ditangani, sehingga memerlukan perhatian yang khusus.

3) Score $100 \%$, Green $\rightarrow$ Efisien

Keterangan :

Kondisi proyek aman dan terdapat score yang sesuai dengan harapan.

\section{HASIL DAN PEMBAHASAN}

1. Karakteristik Responden

Karakteristik responden merupakan gambaran secara umum tentang keadaan dan latar belakang responden yang berkaitan dan berpengaruh terhadap kegiatannya dalam menjalankan usahanya. Responden dalam penelitian ini adalah UMKM Pengolahan kurma salak "Wedi" yang masih bertahan dan melakukan produksi, yaitu sebanyak 3 UMKM antara lain UMKM Bunda Arum, UMKM Shanum, dan UMKM Barokah. Survey dilakukan kepada pelaku UMKM Pengolahan kurma salak "Wedi". Karakteristik responden berdasarkan jenis kelamin, usia, tingkat pendidikan, dan lama usaha dapat dilihat pada tabel 1

Tabel 1 Karakteristik Responden

\begin{tabular}{lcc}
\hline \multirow{2}{*}{ Uraian } & \multicolumn{2}{c}{ UMKM Yang bertahan } \\
\cline { 2 - 3 } & $\begin{array}{c}\text { Jumlah } \\
\text { (Unit) }\end{array}$ & $\begin{array}{c}\text { Persentase } \\
(\%)\end{array}$ \\
\hline $\begin{array}{l}\text { Jenis Kelamin } \\
\text { Laki-laki }\end{array}$ & 0 & 0 \\
Perempuan & 3 & 100 \\
\hline Usia & & \\
$20-40$ & 1 & 33,33 \\
$41-55$ & 2 & 66,67 \\
\hline
\end{tabular}

\begin{tabular}{lcc}
\multicolumn{3}{l}{ Tingkat Pendidikan } \\
SD & 0 & 0 \\
SMP & 0 & 0 \\
SMA & 2 & 66,67 \\
D1-S3 & 1 & 33,33 \\
\hline Lama Usaha & \\
<3 Tahun & 0 & 0 \\
$>4$ Tahun & 3 & 100 \\
\hline \multicolumn{2}{l}{ Sumber : Data Primer (diolah) 2021}
\end{tabular}


Jenis kelamin responden didominasi oleh perempuan dengan persentase $100 \%$. Hal ini menunjukkan bahwa perempuan sebagai pelaku usaha pengolahan kurma salak "Wedi" di Desa Wedi memiliki kontribusi bagi perekonomian rumah tangganya. Usia didominasi oleh responden yang berumur di antara 41-45 tahun dengan persentase $66,67 \%$. Hal ini menunjukkan bahwa mayoritas pelaku usaha pengolahan kurma salak "Wedi" masih termasuk generasi umur produktif.

Tingkat pendidikan responden didominasi pada pendidikan tingkat SMA dengan persentase $66,67 \%$. Hal ini menunjukkan bahwa mayoritas pelaku usaha pengolahan kurma salak "Wedi" telah mendapat pendidikan yang cukup tinggi. Pendidikan yang tinggi berperan dalam menghasilkan lulusan yang berpontensi untuk berwirausaha.
Lama usaha didominasi oleh usaha yang berdiri sejak awal adanya inovasi pengolahan kurma salak "Wedi" yaitu lebih dari 4 tahun dengan persentase $100 \%$. Hal ini menunjukkan UMKM yang masih bertahan didominasi oleh UMKM yang berdiri paling lama.

\section{Biaya Produksi}

Biaya produksi merupakan kas yang dikorbankan untuk memproduksi atau memperoleh barang atau jasa yang diharapkan akan memperoleh manfaat atau keuntungan dimasa yang akan datang. Menurut Rahardja (2006), biaya produksi dibagi menjadi dua yaitu biaya tetap dan biaya variabel. Menurut Rodjak (2006) untuk menghitung besar biaya total diperoleh dengan menjumlahkan biaya variabel dan biaya tetap. Biaya tetap, biaya variabel, dan biaya total usaha kurma salak "Wedi" selama satu bulan produksi secara rinci dapat dilihat pada tabel 2 . 
Tabel 2 Biaya Total Produksi Kurma Salak "Wedi" Selama Satu Bulan

\begin{tabular}{lrrr}
\hline \multicolumn{1}{c}{ Uraian } & \multicolumn{3}{c}{ UMKM } \\
\cline { 2 - 4 } & Bunda Arum (Rp) & Shanum (Rp) & Barokah (Rp) \\
\hline Biaya Variabel & & & \\
Salak "wedi" & 2.704 .000 & 1.560 .000 & 1.872 .000 \\
Gula Pasir & 480.000 & 180.000 & 348.000 \\
Gula Merah & 0 & 105.000 & 0 \\
Air & 24.300 & 35.000 & 45.000 \\
Kapur Sirih & 40.000 & 20.000 & 30.000 \\
Garam & 4.500 & 2.000 & 3.000 \\
Gas & 285.000 & 114.000 & 190.000 \\
Listrik & 15.000 & 9.000 & 8.000 \\
Kemasan & 726.000 & 435.000 & 605.500 \\
Plastik & 119.000 & 141.000 & 110.500 \\
Pemasaran/Transportasi & 150.000 & 150.000 & 150.000 \\
Upah Tenaga Kerja & 3.120 .000 & 1.820 .000 & 754.000 \\
Sub Total & $\mathbf{7 . 6 6 7 . 8 0 0}$ & $\mathbf{4 . 5 7 1 . 0 0 0}$ & $\mathbf{4 . 1 1 6 . 0 0 0}$ \\
Biaya Tetap & & & \\
Penyusutan Alat & 71.433 & 74.567 & 80.855 \\
Sewa Tempat & 7.167 & 4.167 & 5.416 \\
Sub Total & $\mathbf{7 8 . 6 0 0}$ & $\mathbf{7 8 . 7 3 4}$ & $\mathbf{8 6 . 2 7 1}$ \\
\hline Biaya Total & $\mathbf{7 . 7 4 6 . 4 0 0}$ & $\mathbf{4 . 6 4 9 . 7 3 4}$ & $\mathbf{4 . 2 0 2 . 2 7 1}$ \\
\hline
\end{tabular}

Sumber : Data Primer di olah (2021)

Berdasarkan tabel 2 dapat diketahui besarnya biaya total yang digunakan UMKM dalam proses produksi kurma salak "Wedi" selama satu bulan. Biaya total terbesar selama satu bulan produksi adalah pada UMKM Bunda Arum yaitu sebesar Rp7.746.400. Hal ini dikarenakan UMKM Bunda Arum memproduksi kurma salak paling banyak dibandingkan UMKM
Shanum dan UMKM Barokah. dan biaya total terkecil adalah UMKM Barokah sebesar Rp4.202.271.

\section{Penerimaan}

Penerimaan adalah perkalian antara jumlah produksi dengan harga jual. Secara rinci penerimaan UMKM Pengolahan kurma salak "Wedi" selama satu bulan produksi dapat dilihat pada tabel 3

Tabel 3 Penerimaan Usaha Pengolahan Kurma Salak "Wedi"

\begin{tabular}{lrrrrr}
\hline \multicolumn{1}{c}{ UMKM } & \multicolumn{1}{c}{$\begin{array}{c}\text { Produksi } \\
\text { (gr) }\end{array}$} & \multicolumn{1}{c}{$\begin{array}{c}\text { isi/pes } \\
\text { (gr) }\end{array}$} & $\begin{array}{c}\text { Pes } \\
\text { (Unit) }\end{array}$ & $\begin{array}{c}\text { Harga/pes } \\
(\mathbf{R p})\end{array}$ & $\begin{array}{c}\text { Penerimaan } \\
(\mathbf{R p})\end{array}$ \\
\hline Bunda Arum & 114.750 & 150 & 765 & 13.000 & 9.945 .000 \\
Shanum & 65.250 & 150 & 435 & 15.000 & 6.525 .000 \\
Barokah & 83.625 & 75 & 1.115 & 6000 & 6.690 .000 \\
\hline
\end{tabular}

Sumber : Data Primer di olah (2021) 
Tabel 3 menunjukkan bahwa penerimaan UMKM pengolahan kurma salak "Wedi" selama satu bulan produksi secara berturut-turut dari yang terbesar adalah UMKM Bunda Arum sebesar Rp9.945.000, UMKM Barokah sebesar Rp6.690.000, dan yang paling kecil adalah UMKM Shanum sebesar Rp6.525.000. Penerimaan UMKM Bunda Arum paling besar karena produksi kurma salaknya paling banyak dibandingkan UMKM lainnya.

\section{Keuntungan}

Keuntungan merupakan tujuan utama dari setiap bisnis. Pelaku UMKM Pengolahan kurma salak "Wedi" dapat mengetahui besarnya keuntungan selama satu bulan produksi dengan cara mengurangi biaya penerimaan dengan biaya total produksi. Secara rinci keuntungan UMKM Pengolahan kurma salak "Wedi" selama satu bulan produksi dapat dilihat pada tabel 4 .

Tabel 4 Keuntungan Usaha Pengolahan Kurma Salak "Wedi"

\begin{tabular}{lccr}
\hline UMKM & $\begin{array}{c}\text { Biaya Total } \\
(\mathbf{R p})\end{array}$ & $\begin{array}{c}\text { Penerimaan } \\
(\mathbf{R p})\end{array}$ & $\begin{array}{c}\text { Keuntungan } \\
(\mathbf{R p})\end{array}$ \\
\hline Bunda Arum & 7.746 .400 & 9.945 .000 & 2.198 .600 \\
Shanum & 4.649 .734 & 6.525 .000 & 1.875 .266 \\
Barokah & 4.202 .271 & 6.690 .000 & 2.487 .729 \\
\hline
\end{tabular}

Sumber : Data Primer di Olah (2021)

Berdasarkan informasi dari tabel 4 dapat diketahui keuntungan selama satu bulan produksi usaha pengolahan kurma salak "Wedi" yang paling besar adalah Rp2.487.729 pada UMKM Barokah, meskipun jumlah produksi kurma salak pada UMKM Barokah lebih sedikit dibandingkan UMKM Bunda Arum. Hal ini dikarenakan biaya total pada UMKM Barokah lebih sedikit dibandingkan UMKM Bunda Arum. Sedangkan keuntungan yang terkecil pada UMKM Shanum yaitu sebesar Rp1.875.266. Hal ini dikarenakan UMKM Shanum memproduksi kurma salak paling sedikit dibandingkan UMKM lainnya.

\section{Profitabilitas}

Untuk mengukur tingkat keuntungan suatu perusahaan, digunakan rasio profitabilitas atau rasio keuntungan. Besarnya profitabilitas dapat dihitung apabila keuntungan sudah diketahui. Pelaku UMKM pengolahan kurma salak "Wedi" dapat mengetahui besarnya profitabilitas dengan membagi besarnya keuntungan dengan total biaya dan dikali $100 \%$. Secara rinci besarnya profitabilitas 
atau tingkat keuntungan UMKM

Pengolahan kurma salak "Wedi" selama satu bulan produksi dapat dilihat pada tabel 5

Tabel 5 Profitabilitas Usaha Pengolahan Kurma Salak "Wedi"

\begin{tabular}{lrrr}
\hline UMKM & Total Biaya $(\mathbf{R p})$ & Keuntungan $(\mathbf{R p})$ & Profitabilitas (\%) \\
\hline Bunda Arum & 7.746 .400 & 2.198 .600 & 28,38 \\
Shanum & 4.649 .734 & 1.875 .266 & 40,33 \\
Barokah & 4.202 .271 & 2.487 .729 & 59,19
\end{tabular}

Sumber : Data Primer di Olah (2021)

Berdasarkan tabel 5 menunjukkan profitabilitas atau tingkat keuntungan masing-masing usaha pengolahan kurma salak "Wedi" lebih dari 1\%. Hal ini menunjukkan usaha pengolahan kurma salak "Wedi" di Desa Wedi sudah menguntungkan. Profitabilitas atau tingkat keuntungan terbesar pada usaha pengolahan kurma salak "Wedi" adalah 59,19\% yaitu pada UMKM Barokah. Hal ini menunjukkan UMKM Barokah setiap investasi Rp100 akan memperoleh keuntungan sebesar Rp59,19. Sedangkan UMKM yang memperoleh profitabilitas atau tingkat keuntungan paling rendah adalah UMKM Bunda Arum yaitu sebesar Rp28,38\%. Hal ini dikarenakan total biaya produksi yang tinggi dan keuntungan yang didapatkan tidak terlalu besar

\section{Efisiensi}

Analisis efisiensi biaya pada penelitian ini menggunakan metode Data Envelopment Analysis (DEA). Prinsip kerja DEA adalah membandingkan data input dan output dari suatu organisasi data dengan data input dan output lainnya pada DMU yang sejenis. Analisis efisiensi pada penelitian ini menggunakan model CRS (constant returns to scale). Hasil analisis efisiensi UMKM Pengolahan kurma salak "Wedi" menggunakan metode DEA secara rinci dapat dilihat pada tabel 6.

Tabel 6 Efisiensi Biaya Usaha Pengolahan Kurma Salak "Wedi"

\begin{tabular}{clccc}
\hline \multicolumn{1}{c}{ Analisis } & \multicolumn{1}{c}{ DMU } & \multicolumn{1}{c}{ Skor } & Efisiensi & Kondisi \\
\hline \multirow{3}{*}{ CRS } & Bunda Arum & $100 \%$ & Efisien & Green \\
& Shanum & $100 \%$ & Efisien & Green \\
& Barokah & $100 \%$ & Efisien & Green \\
\hline
\end{tabular}

Sumber : Data Primer Analisis DEA (diolah), 2021

Berdasarkan tabel 6 dapat diketahui hasil perhitungan nilai efisiensi biaya menggunakan metode Data Envelopement
Analysis (DEA) dengan asumsi Constant Return to Scale (CRS) pada masing masing UMKM Pengolahan salak "Wedi" di Desa 
Wedi. Berdasarkan hasil perhitungan dapat diketahui semua UMKM Pengolahan kurma salak "Wedi" yang masih bertahan yaitu UMKM Bunda Arum, UMKM Shanum, dan UMKM Barokah telah beroperasi secara efisien. Hal ini terlihat dari skor efisiensi sebesar $100 \%$ dan berwarna hijau, artinya penggunaan input oleh UMKM pengolahan kurma salak "Wedi" untuk menghasilkan output sudah optimal. Selain itu dalam proses produksi tidak terjadi pemborosan pemakaian input sehingga output yang dihasilkan optimal.

\section{KESIMPULAN DAN SARAN}

\section{Kesimpulan}

Berdasarkan hasil penelitian yang dilakukan di UMKM pengolahan Kurma salak "Wedi" di Desa Wedi Kecamatan Kapas Kabupeten Bojonegoro mengenai profitabilitas dan efisiensi biaya UMKM pengolahan kurma salak "Wedi" dapat disimpulkan bahwa :

1. Semua UMKM pengolahan kurma salak "Wedi" sudah menguntungan dengan profitabilitas pada masingmasing UMKM pengolahan kurma salak "Wedi" yaitu UMKM Bunda Arum sebesar 28,38\%, UMKM Shanum sebesar 40,33\%, dan UMKM Barokah sebesar 59,19\%.
2. Semua UMKM pengolahan kurma salak "Wedi" di Desa Wedi yang masih bertahan telah efisien berdasarkan hasil analisis efisiensi menggunakan metode Data Envelopement Analysis (DEA) diperoleh skor $100 \%$.

\section{Saran}

Berdasarkan hasil penelitian diatas maka peneliti dapat memberikan saran kepada pelaku usaha UMKM pengolahan kurma salak "Wedi" sebagai berikut :

1. Bagi pelaku UMKM pengolahan Kurma salak "Wedi" yang tingkat memperoleh keuntungan (profitabilitas) yang cukup tinggi untuk mempertahankan dan meningkatkan profitabilitas usaha pengolahan kurma salak "Wedi" guna menjaga keberlangsungan usaha pengolahan kurma salak "Wedi"

2. Bagi pelaku UMKM pengolahan kurma salak "Wedi" yang telah mencapai efisiensi biaya untuk mempertahankan efisiensinya agar kelangsungan usaha pengolahan kurma salak "Wedi" dapat terjaga

\section{DAFTAR PUSTAKA}

Abd. Rahim dan Riah Retno Dwi Hastuti. 2007. Ekonomika Pertanian, Pengantar Teori dan Kasus : Penebar Swadaya 
Anggraita. 2012. Evaluasi Efisiensi Kereta Api Penumpang di Pulau Jawa dengan Metode Data Envelopement Analysis (DEA) Tahun 2008-2010. Tesis FE UI

Darsono dan Ashari. 2005. Pedoman Praktis Memahami Laporan Keuangan. Yogyakarta : CV. Andi Offset

Fahmi. 2014. Analisis Laporan Keuangan. Bandung : Alfabeta

Firdaus, M. 2008. Manajemen Agribisnis. Bumi Aksara. Jakarta

Ibrahim, Y. 2003. Studi Kelayakan Bisnis. PT Rineka Cipta. Jakarta.

Indah Susilowati dan Huri Daman M. 2004. Pengukuran Efisiensi Relatif Emiten Perbankan dengan Metode Data Envelopement Analysis (DEA). Dinamika Pembangunan. Vol. 1 No. 2

Pearce J. A. \& Richard, B. R. (2008). Manajemen Strategis Formulasi Implementasi dan Pengendalian. Jakarta: Salemba Empat

Rahardja, P. dan Manurung, M. 2006. Teori Ekonomi Mikro, Suatu Pengantar. Edisi Ketiga. Jakarta: Fakultas Ekonomi Universitas Indonesia
Rencana Strategis Kementrian Koperasi dan Usaha Kecil dan Menengah Repubilk IndonesiaTahun 20122014

Reeve, James M. et. Al. 2011. Pengantar Akuntansi, terj. Dian. Jakarta : Salemba Empat

Rodjak, A. 2006. Manajemen Usahatani. Giratuna. Bandung.

Santoso. 2010. Statistik Parametrik. Gramedia. Jakarta.

Sugiyono. 2018. Metode Penelitian Kuantitatif Kualitatif dan R \& D. Bandung : Alfabeta

Supriyanto, Achmad S. dan Machfudz, Mashuri. 2010. Metodologi RisetManajemen Sumber Daya Manusia. Malang : UIN Maliki Press

Sutrisno. (2009), Manajemen Keuangan Teori, Konsep dan Aplikasi, Edisi Pertama, Cetakan Ketujuh, Penerbit Ekonisia, Yogyakarta.

Yogi, 2006. Ekonomi Manajerial. 2nd ed. Jakarta: Kencana. 